\title{
GIAMBATTISTA VICO EN UNA NUEVA CLAVE
}

\section{Ferdinand Fellmann}

(Universidad T. de Chemnitz)

RESUMEN: El Autor expone su interpretación de Vico y las circunstancias que, desde los años '70, han rodeado sus propuestas. A su vez, el Autor muestra resumidos en cinco los conceptos-clave que han guiado su investigación viquiana desde 1970: primado de la fantasía; primitivismo cultural; religión; origen del lenguaje; y barbarie de la reflexión.

Palabras Clave: Vico, $350^{\circ}$ Aniversario, crítica viquiana, fantasía, cultura, lenguaje, barbarie de la reflexión, F. Fellmann.

\section{Giambattista Vico in a new key}

ABSTRACT: The author explains his interpretation of Vico and the critical circumstances that have surrounded his proposals since the 1970s. In turn, the Author clearly shows the five key concepts that have guided his Viquian research since 1970: primacy of fantasy; cultural primitivism; religion; origin of language; and barbarism of reflection.

KEYWORDS: Vico, 350 th Anniversary, viquian critique, fantasy, culture, language, barbarism of reflection, $F$. Fellmann.

\section{Vico in una nuova chiave di lettura}

RiASSUNTO: Nel presente contributo l'Autore espone la propria interpretazione di Vico e le circostanze che, a partire dagli anni '70, hanno orientato le sue proposte. Inoltre, l'Autore spiega i cinque concetti chiave che hanno guidato la sua ricerca vichiana dal 1970: primato della fantasia, primitivismo culturale, religione, origine della lingua e barbarie di riflessione.

PAROLE CHIAVE: Vico, $350^{\circ}$ Anniversario, critica vichiana, fantasia, cultura, linguaggio, barbarie della riflessione, F. Fellmann.

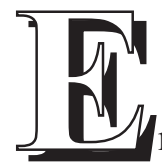

n mi clásico Das Vico-Axiom: Der Mensch macht die Geschichte [El axioma-Vico: El humano hace la historia] (1976) he interpretado la Ciencia nueva de Vico a la luz de la antropología cultural. Mi tesis era que aunque el hombre es el único autor del mundo de las naciones, él no puede gobernar el curso de la historia con la voluntad o la conciencia, como Karl Marx creyó. Mi perspectiva sociológica sobre Vico fue atacada duramente tanto por los idealistas como por los materialistas.

Este artículo responde a una invitación expresa por parte de la Dirección de la Revista para este volumen especial por el $350^{\circ}$ Aniversario del nacimiento de G. Vico, habiendo superado los criterios de valoración y del proceso de aceptación. 
Para los idealistas mi concepción de la historia era demasiado naturalista, mientras que los marxistas acusaron mi trabajo de ser un revisionismo "tardoburgués".

En mi libro partí de la influyente concepción idealista de la historia presentada en la filosofía del espíritu de Hegel, que había sido predominante en Italia desde Benedetto Croce y desde Ernst Cassirer en Alemania. Mi pregunta principal era: cuáles fueron las condiciones metodológicas bajo las que Vico fue capaz de reconstruir y justificar la historia universal como un todo con sentido, sin aceptar, por un lado, la guía divina de los asuntos humanos (como en la teología de la historia de Bossuet) o, por otro lado, el constructivismo de Descartes y Hobbes (que hace un razonamiento lógico del estándar de la acción humana). La originalidad de Vico consiste en el descubrimiento y descripción de una forma primordial de la interacción social que es constitutiva de la continuidad histórica. Sobre la base de una nueva teoría del mito, él pasa a representar el sistema natural del conocimiento poético, que es inherente a la organización del mundo social.

El conocimiento poético está ligado al sentido común, orientado no a principios a priori sino a lo "usual y necesario" para la vida social. La verdad no es semánticamente definida como el acuerdo de idea y objeto, sino como un proceso de hacer las ideas verdaderas a través de un adecuado comportamiento social. La rehabilitación de Vico del sentido común continúa la tradición humanística de la hermenéutica, contraria al racionalismo cartesiano que está programado para aclarar y distinguir la percepción. En su temprano escrito De nostri temporis studiorum ratione (1708) Vico defiende lo probable, lo "muy-similar", como la instancia que localiza lo individual en el ambiente social y estabiliza las creencias. Esto es debido no al razonamiento lógico sino a la fantasía creativa, el ingenium, sin el que el mundo de la cultura llegaría a un final.

Das Vico-Axiom explica cómo el concepto central de Vico de la praxis poética o poesis influencia los diversos aspectos de su filosofía de la historia: su tratamiento del concepto teológico de tradición (capítulo I: "La verdad de los teólogospoetas"), su crítica del ideal cartesiano de ciencia (capítulo II: "Hércules contra Prometeo"), su intento de reconciliar el derecho natural con la filosofía política de Hobbes (capítulo III: "Filosofía de la autoridad"), la idea de una antropología histórica (capítulo IV: "Humanidad inhumana"), y su cambio de la historia política a la cultural debido a la hermenéutica del entendimiento histórico (capítulo V: "Historia de las ideas"). El libro concluye al mostrar que el concepto de acción poética en la Scienza nuova sirve como bisagra para una interpretación anti-racionalista de la fórmula verum-factum en los tempranos escritos filosóficos de Vico.

Al enfatizar el concepto central de productividad poética, he empleado los métodos de la fenomenología, particularmente en el análisis de las diversas formas de experiencia comprendidas por la visión de Vico del mundo de la vida social. A pesar de este nuevo método, evité modernizar exageradamente a Vico. Yo veo la Ciencia 
nueva en el contexto intelectual de su tiempo, desarrollando numerosas comparaciones con otros filósofos de la historia del siglo XVIII, especialmente Fontenelle, Voltaire, Rousseau y Kant. Actualmente, interpreto la Ciencia nueva en el marco de la filosofía moderna de la vida, incluyendo aspectos socio-biológicos, etnológicos y éticos. En la visión de la tesis de Vico de que la naturaleza es el proceso de llegar a ser humano, mi acceso fenomenológico hace evidente sorprendentes paralelismos entre la Ciencia nueva de Vico y la psicología y la sociología modernas.

En las páginas que siguen son enumerados los conceptos clave que han guiado mi investigación desde 1970.

\section{Primero, LA PRIMACía de la FANTASíA}

En la formación del mundo social la fantasía juega un papel esencial (SN44, $\S 375)$. La Ciencia nueva presenta un sistema de conocimiento preconceptual que es denominado «sabiduría poética». Esta sabiduría no resulta de intereses teóricos sino de las necesidades prácticas de vivir juntos. Por tanto, los mitos no son los precursores de justificación epistémica, sino el medio primario de la socialización. Los mitos sociales resultan de fuentes emocionales profundas que Vico llama «mondo delle menti umane» $(S N 44, \S 2)$. La desenfrenada expresión de las emociones requiere formas sociales de vida. Estas formas de vida social consisten en imágenes míticas que no se refieren a hechos objetivos, sino a la articulación de estados mentales. Así, la sabiduría poética es conocimiento como un medio para dar seguridad y orientación al individuo en el mundo social.

El concepto de la productividad mental, la poiesis en lugar de la prâxis, es una alternativa al racionalismo moderno que apunta a una construcción lógica del mundo. La sabiduría poética corresponde a la sabiduría del cuerpo que está constantemente articulando las necesidades vitales en forma de representaciones míticas. Los seres humanos primitivos producen representaciones que ellos dan por sentadas: fingunt simul creduntque (SN44, § 376).

El psicólogo William James ha llamado a esta retroalimentación mental La voluntad de creer. La teoría del mito de Vico ha inspirado al sociólogo francés Georges Sorel. En la visión de Sorel la "verdad" del mito social consiste en las consecuencias prácticas que resultan de él. Considera que este es el único modo posible para los hombres de ascender a una vida ética apoyada por el carácter de lo sublime que Vico atribuye a los teólogos poetas.

\section{SEgUndo, LA PRIMITIVA ESCENA de la CULTURA HUMANA}

Vico considera al hombre como a una criatura que está arraigada en algún lugar. Explica la llegada de lo sedentario en el siguiente escenario.

Los primeros humanos eran gigantes errando en el paisaje. Durante las tormentas se asustaban y se retiraban a cuevas para abrigarse. De forma diferente a la 
alegoría de la caverna platónica, las grutas de Vico son un lugar de humanización. La cueva como el origen de la ética humana se muestra como en la relación entre masculino y femenino:

«Col conato altresì incominciò in essi a spuntare la virtù dell'animo, contenendo la loro libidine bestiale di esercitarla in faccia al cielo, di cui avevano uno spavento grandissimo; e ciascuno di essi si diede a strascinare per sé una donna dentro le loro grotte e tenerlavi dentro in perpetua compagnia di lor vita; e si usarono con esse la venere umana al coverto, nascostamente, cioè a dire con pudicizia; e sì incominciarono a sentir pudore, che Socrate diceva esser "il colore della virtù"» $(S N 44, \S 504){ }^{1}$

Este pasaje se confirma por el modo en que los modernos biólogos hipotetizan la evolución del amor erótico humano.

Para explicar el cambio de lo animal al sentimiento humano de la vida Vico no usa la noción de teleología natural. El proceso de humanización sigue lo que Wilhelm Wundt ha llamado el principio de la heterogonía de los propósitos (fines). Las consecuencias de una acción se extienden más allá del propósito original y dan lugar a nuevos motivos con nuevos efectos, $v$. gr., una organización cada vez mayor a través de una auto-creación instintiva.

\section{Tercero, LA FE RELIGIOSA}

El hombre primitivo pensaba que el trueno era un mensaje o mandato de un poder divino: "todas las cosas están llenas de Júpiter" - Jovis omnia plena- (SN44, $\S 379$ ). Dos características de la divinidad: statore y fermatore (§ 504) también como sotere o salvatore (§ 379). Esto presupone un acto de negación: «perche non gli fulminò» -un acto mental que los animales no son capaces de llevar a cabo.

En la visión de Vico, la fe religiosa no es implementada por el Creador divino en la mente humana. La fe es un resultado de responder al entorno natural. Con esto, la Scienza nuova de Vico puede ser considerada como el inicio de la moderna sociología de la religión. Los atributos tradicionales del Todopoderoso no surgen de la cabeza, sino que son originados de las imágenes del cuerpo concreto que impresionaron a los nativos: «fortissimo» y «ottimo». Por ello, Hércules en lugar de Prometeo figura como el modelo mítico de la idea de historia.

1. N.E.- El texto original está escrito en inglés, pero el Autor cita en italiano. «Con el conato también comenzó a despuntar en ellos la virtud del ánimo, conteniéndose de ejercitar su líbido bestial de cara al cielo, del que tenían un gran temor; y cada uno de ellos se llevó a rastras consigo una mujer dentro de sus grutas y las mantuvieron allí en perpetua compañía durante la vida; y así hicieron con ellas el acto sexual humano a cubierto, ocultos, es decir, con pudicia; y así comenzaron a sentir pudor, que Sócrates decía que era el "color de la virtud"». 


\section{CuARTO, EL ORIGEN DEL LENGUAJE}

La evolución del lenguaje comienza con el lenguaje silencioso de los gestos y de los consejos $(S N 44, \S 32 ; 34)$. Los humanos, como todos los animales, tienen la necesidad de expresar sus sentimientos y hacerse ellos mismos entendibles ( $\S 34 ; 456)$. La fuerza de la expresión es muy fuerte ( $\S \S 431 ; 434)$. Esto corresponde a la dominación de los sentidos con débiles facultades intelectuales ( $\$ 375$ ). En el estado de naturaleza «uomini tutti robuste forze di corpo, che, urlando, brontolando, spiegavano le loro violentissime passioni» (§ 377). ${ }^{2}$ Solo gradualmente los humanos van aprendiendo a expresar sus emociones de un modo más diferenciado. Consecuentemente, el lenguaje silente de los gestos llega a ser un lenguaje de narradores de historia. Este lenguaje desarrolla los así llamados «universali fantastici», representaciones generales que concentran el sentido de las narraciones mitológicas.

El lenguaje humano no es meramente expresivo, es también comunicativo. La comunicación está dirigida a influenciar a otras personas. Por los consejos y los gestos los primeros humanos querían decirles a otros qué tenían que hacer, ellos mandaban por signos. Tales signos Vico los llama «palabras reales» hechas de materia corpórea (SN44, $\S \S 378 ; 379)$. Las funciones del cuerpo como un argumento que no permite objeción alguna. Por tanto, la poesis de los teólogos poéticos corresponde a la voluntad de poder, y no tiene nada de lo lúdico y sereno de la poesía moderna.

En el ejercicio del poder social, la teoría del lenguaje de Vico difiere de la de Herder, con quien Vico ha sido a veces comparado. Herder, en la línea del Romanticismo, piensa que el lenguaje de las emociones unirá a todos los seres humanos. Para Vico la expresión de las emociones crea una distancia entre el hablante y el oyente, y solo a través de la obediencia se produce el proceso de socialización. En esta perspectiva el sentimiento pragmático es más fuerte que el empático. Vico interpreta la conexión entre acción social y lenguaje desde la visión de las estructuras jerárquicas, $\mathrm{y}$ en esto difiere no solo de Herder, sino también de Wilhelm von Humboldt, quien considera que el lenguaje es un modo cognitivo de hacer-mundo. Vico, sin embargo, está preocupado con el mantenimiento de la ley social y el orden, y consecuentemente él denomina su ciencia nueva una «filosofía de la autoridad».

\section{QUINTO, LA BARBARIE DE LA REFLEXIÓN}

De acuerdo con el patrón del desarrollo individual el curso de las culturas es cíclico, y un progreso de la humanidad es obvio. Pero al fin, cuando la reflexión supera el sentido común, el mundo social se descompone y entra en una última fase,

2. N.E.- «[...] hombres todos ellos de robustas fortalezas corpóreas, [...] aullando y rugiendo desplegaban sus violentas pasiones». 
que en la visión de Vico tiene lugar en la Europa contemporánea, como resultado del racionalismo de la Ilustración. Los humanos se han distanciado ellos mismos tanto de las condiciones naturales de vida que un retorno al barbarismo de los sentidos es inevitable. Este corresponde a la naturaleza del hombre, a quien Vico no entiende ontológicamente, sino en evolución:

«Natura di cose altro non è che nascimento di esse in certi tempi e con certe guise, le quali sempre che sono tali, indi tali e non altre nascon le cose» $(S N 44, \S 147) .^{3}$

La teoría de Vico de los ricorsi o regresos históricos nos recuerda el criticismo cultural en La Decadencia de Occidente de Oswald Spengler (1917). Más elaborada es la analogía respecto a Urmensch und Spätkultur de Arnold Gehlen (1956). Gehlen considera que el ritual no manifiesta ser el modelo arcaico específico de acción, y en este aspecto las descripciones de Gehlen están próximas a la idea de Vico de los teólogos poéticos. También el famoso artículo de Francis Fukuyama El fin de la Historia (1989) muestra ciertas afinidades con la filosofía de la historia de Vico en la medida en que Fukuyama considera la democracia el estadio ineficiente final del progreso histórico. No pretendo que Vico haya inspirado a estos pensadores modernos al detalle, pero me gustaría considerar la Ciencia nueva como un ejemplo excepcional de reconstruir el mundo social de un modo realístico y pragmático que no ha perdido nada de su relevancia. Last, but not least, un panorama para una futura investigación se encuentra en Las Leyes de los Media. La ciencia nueva de Marshall y Eric McLuhan (1988). Refiriéndose a la visión de Finnegans Wake McLuhan escribe en el prefacio del libro:

«Vico en particular apuntó "las modificaciones de nuestras propias mentes humanas" como el área crucial, mientras que trata de encontrar un camino para leer y escribir el "diccionario mental"».

La filosofía postmoderna de la cultura descubrirá nuevas palabras clave del diccionario mental. Espero que mi entendimiento de la Ciencia nueva de Vico contribuya a ese proyecto.

[Traducción del inglés por Pablo Badillo O'Farrell]

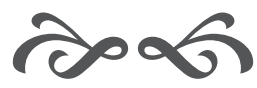

3. N.E.- «La naturaleza de las cosas no es otra que el nacimiento de estas en ciertos tiempos y bajo ciertas circunstancias, las cuales, siempre que son las mismas, tales y no otras nacen las cosas». 